\title{
Temperature Dependence of Sensors Based on Silver-Decorated Nitrogen-Doped Multiwalled Carbon Nanotubes
}

\author{
Eduardo Gracia-Espino, ${ }^{1,2,3}$ Bernabé Rebollo-Plata,,4 \\ Hugo Martínez-Gutiérrez, ${ }^{5}$ Emilio Muñoz-Sandoval, ${ }^{3}$ Florentino López-Urías, ${ }^{3}$ \\ Morinobu Endo, ${ }^{6}$ Humberto Terrones, ${ }^{7}$ and Mauricio Terrones ${ }^{6,8,9}$ \\ ${ }^{1}$ Department of Physics, Umeå University, 90187 Umeå, Sweden \\ ${ }^{2}$ Department of Chemistry, Umeå University, 90187 Umeå, Sweden \\ ${ }^{3}$ Advanced Materials Department, IPICYT, Camino a la Presa San José 2055, Colonia Lomas $4{ }^{a}$ Sección, \\ 78216 San Luis Potosí, SLP, Mexico \\ ${ }^{4}$ Instituto Tecnológico Superior de Irapuato, Carretera Irapuato-Silao Km. 12.5 Colonia El Copal, 36821 Irapuato, GTO, Mexico \\ ${ }^{5}$ Centro de Nanociencias y Micro y Nanotecnologías, Instituto Politécnico Nacional, Luis Enrique Erro S/N, \\ Colonia Zacatenco, 07738 Delegación Gustavo A. Madero, DF, Mexico \\ ${ }^{6}$ Institute of Carbon Science and Technology, Shinshu University, 4-17-1 Wakasato, Nagano 380-8553, Japan \\ ${ }^{7}$ Department of Physics, Applied Physics and Astronomy, Rensselaer Polytechnic Institute, Troy, NY 12180, USA \\ ${ }^{8}$ Faculty of Engineering, Shinshu University, 4-17-1 Wakasato, Nagano 380-8553, Japan \\ ${ }^{9}$ Department of Physics, Department of Materials Science and Engineering and Materials Research Institute, \\ The Pennsylvania State University, 104 Davey Lab., University Park, PA 16802-6300, USA
}

Correspondence should be addressed to Florentino López-Urías; flo@ipicyt.edu.mx

Received 6 August 2015; Accepted 8 December 2015

Academic Editor: Banshi D. Gupta

Copyright (C) 2016 Eduardo Gracia-Espino et al. This is an open access article distributed under the Creative Commons Attribution License, which permits unrestricted use, distribution, and reproduction in any medium, provided the original work is properly cited.

\begin{abstract}
Vapor sensors are easily fabricated onto alumina substrates using foils of silver-decorated nitrogen-doped multiwalled carbon nanotubes $\left(\mathrm{CN}_{X}\right.$-MWNTs-Ag) as active sensing material. The vapor sensors are tested using carbon disulfide, acetone, ethanol, and chloroform vapors. The $\mathrm{CN}_{X}$-MWNTs are produced by chemical vapor deposition process and then decorated with $14 \mathrm{~nm}$ Ag nanoparticles (Ag-NPs). The samples are characterized using scanning electron microscopy, transmission electron microscopy, and X-ray diffraction. Our results demonstrate that Ag-decorated $\mathrm{CN}_{X}-\mathrm{MWNTs}$ exhibit a better response and sensitivity when compared with pristine $\mathrm{CN}_{X}$-MWNTs based sensors, making them promising candidates for air-pollutants environmental monitoring. The temperature effect on the sensor performance is also studied; we found that the detection mechanism could be tuned from physisorption, at room temperature, to chemisorption at higher working temperature. Finally, first-principles density functional calculations are carried out to understand the interactions between the systems involved in the sensors, finding good agreement between experimental results and the theoretical approach.
\end{abstract}

\section{Introduction}

Carbon nanotubes (CNTs) have proved to be excellent candidates for sensing applications. Multiwalled carbon nanotubes (MWCNTs) based sensors are sensitive to a variety of gases such as $\mathrm{NH}_{3}, \mathrm{NO}, \mathrm{NO}_{2}, \mathrm{H}_{2}, \mathrm{SF}_{6}$, and $\mathrm{Cl}_{2}$ [1-3]. Different devices have been used to fabricate CNTs sensors for the detection of vapors and gases; the most common are field effect transistors [4] and resistors [5-8]. Because of their simplicity and simple fabrication, the resistor is a frequently used arrangement, where the change in electrical conductivity is monitored when the sensor is exposed to various atmospheres. One common disadvantage of carbon nanotubes based gas sensors is the potential interference from 
relative humidity at room temperature, the slow recovery, and poor selectivity. There have been a variety of attempts to overcome these limitations, such as heat treatment, ultraviolet light irradiation, increasing carrier gas flux, and modification of CNTs with functional groups or other additives [9].

Chemically functionalized CNTs have been used as an active component in sensor devices; the addition of functional groups such as carboxylic acid in CNTs has demonstrated enhanced sensitivity to ethanol [10] and nitric oxide gas [11]. Other approaches involve the incorporation of carbon nanotubes into polymers to form nanocomposites [12]. Nanocomposite materials such as CNTs decorated with metal or metal oxide nanoparticles have been proposed as an active component in gas sensing devices. These nanoparticlesnanotube systems have attracted much attention because of their unique and enhanced sensitivity toward gaseous species such as $\mathrm{H}_{2}, \mathrm{H}_{2} \mathrm{~S}[8,13,14], \mathrm{NO}_{2}[5,8,15], \mathrm{NH}_{3}$, and $\mathrm{CO}[15,16]$ compared to pure nanotube gas sensors [17].

Nitrogen-doped MWNTs ( $\mathrm{CN}_{X}$-MWNTs) have also been shown to be an excellent approach to overcoming some limitations which exhibit pure carbon nanotube systems in gas sensing applications $[6,18,19]$ due to their higher chemical reactivity at the surface. The use of $\mathrm{CN}_{X}$-MWNTs avoids the use of hazardous strong acidic treatments and additionally, these materials are better candidates for anchoring diverse nanoparticles [20-22] and fabrication of more sensitive sensors. The decoration of CNTs with silver nanoparticles (Ag-NPs) has been extensively explored [23-26], and the resulting hybrid composites have proved to be an excellent active component for sensing biological materials [27, 28].

By taking advantage of the facility to deposit metallic nanoparticles on $\mathrm{CN}_{X}$-MWNTs and the high affinity that $\mathrm{Ag}$ exhibits to sulfur containing molecules, we have fabricated a carbon disulfide $\left(\mathrm{CS}_{2}\right)$ gas sensor. We selected $\mathrm{CS}_{2}$ as a targeting gas because of its potential hazard to human health. Nowadays, the most feasible and widely accepted technique for the analysis of reduced sulfur compounds (RSC) in air is gas chromatography (GC) [29]. $\mathrm{CS}_{2}$ is one of the most abundant RSCs in the environment [30]. Pure $\mathrm{CS}_{2}$ is highly volatile, the vapor can explode in the air, and the exposure affects the nervous system and developing fetus; its chronic exposure may lead to kidney and liver damage [31]. For these reasons and due to the difficulty in the detection and quantification of $\mathrm{CS}_{2}$ vapor, the developing of portable, sensitive, and selective sensors is needed to overcome the timeconsuming and tedious processes of sampling and offline analytical protocols in the laboratory. Some considerable efforts have been done to detect $\mathrm{CS}_{2}$; some reports use metal oxide nanomaterials such as $\mathrm{CeO}_{2}$ [32] and doped $\mathrm{TiO}_{2}$ [33], while others use quartz crystals as a surface acoustic wave sensor [34], often resulting in complex experimental setups. But despite this effort, the $\mathrm{CS}_{2}$ vapor detection is still a challenge and developing materials used for manufacturing a portable sensor with improved properties is an ongoing investigation.

In the present work, we propose the use of Ag-decorated $\mathrm{CN}_{X}$-MWNTs-Ag as sensor devices. Different fabricated sensors were tested using $\mathrm{CS}_{2}$, ethanol, acetone, and chloroform vapors. Thermal effects are also considered on the sensors performance. In addition, first-principles calculations are carried out in order to understand the interaction between carbon nanotubes, Ag-NPs, and the involved organic molecules.

\section{Experimental Details}

2.1. $C N_{X}-M W N T s-A g$ Production and Sensors Fabrication. $\mathrm{CN}_{X}-\mathrm{MWNT}$ are synthesized by chemical vapor deposition (CVD) by pyrolyzing a solution containing $2.5 \mathrm{wt} \%$ of ferrocene and benzylamine at $825^{\circ} \mathrm{C}$ in an $\mathrm{Ar}$ atmosphere for $30 \mathrm{~min}$ [35]. The nitrogen content of these CNTs is around $2 \%[36,37]$. Afterwards generating the $\mathrm{CN}_{X}$-MWNTs, the anchorage process of Ag-NPs is carried out as follows: the $\mathrm{CN}_{X}$-MWNTs are heated at $300^{\circ} \mathrm{C}$ in air during $5 \mathrm{~min}$, in order to modify its surface by adding some oxygenated functional groups. Afterwards, $35 \mathrm{mg}$ of nanotubes is added to $20 \mathrm{~mL}$ of acetone containing silver nitrate $(166 \mu \mathrm{L}$ of a solution $0.1 \mathrm{~N}$, J.T. Baker) in a flask. The suspension is dispersed ultrasonically for one hour. Subsequently, the solution is placed in a water bath at $\sim 50^{\circ} \mathrm{C}$ for 60 minutes. Finally, the solution is filtered using a PTFE membrane with $0.2 \mu \mathrm{m}$ pore size, washed with distilled water, and dried at $110^{\circ} \mathrm{C}$ in a furnace. The Ag-NPs exhibit an average diameter of $14 \mathrm{~nm}$.

For the sensors fabrication, the following steps are followed. (a) Foils formed by dispersed $\mathrm{CN}_{X}$-MWNTs and $\mathrm{CN}_{X}$-MWNTs with Ag-NPs $\left(\mathrm{CN}_{X}-\mathrm{MWNT}-\mathrm{Ag}\right)$ are obtained by vacuum filtration using acetone as a solvent; the concentration of the suspension is selected to provide a homogeneous foil thickness. (b) The foil sensors are cut to obtain a surface of $0.5 \times 4.0 \mathrm{~mm}$. (c) The foils are supported on alumina plates with copper electrodes using silver paint. (d) The electrodes are connected to the source-meter and control system. In order to perform the experiment, the fabricated sensor devices are placed within a quartz tube inside a tubular furnace. The desired vapor is introduced by bubbling Ar gas (Ar flow of $0.3 \mathrm{~L} / \mathrm{min}$ ) into a deposit containing the corresponding liquid.

2.2. Material Characterization Techniques. The characterization of the nanotubes films is carried out using a scanning electron microscope (FEG-SEM, FEI XL30 FEG/SFEG) operated at $3-20 \mathrm{kV}$. The X-ray powder diffraction patterns of all samples were performed using XRD D8 AdvanceBruker AXS, with $\mathrm{Cu} \mathrm{K} \mathrm{K}_{\alpha}$ radiation $(\lambda=1.54060 \AA)$. The operating current and voltage were maintained at $25 \mathrm{~mA}$ and $35 \mathrm{kV}$. High resolution images were taken with HRTEMfield emission Tecnai F30 operated at $300 \mathrm{kV}$. The electrical characterization of each sample was carried out using a SourceMeter (Keithley 2400) with Labview environment. In order to measure the sensing capacity of the foils, these were placed inside a quartz tube with a controlled temperature and atmosphere; a schematic of the experimental setup is shown in Figure S1 in Supplementary Material available online at http://dx.doi.org/10.1155/2016/4319498. Argon gas is used to purge and clean the nanotubes foils. Two different exposure intervals are used: $80 \mathrm{~s}$ for the gas to be detected and $120 \mathrm{~s}$ to purge the system with Ar gas; this process is repeated for at 
least five cycles. We then plotted the normalized resistance $\left(R_{N}\right)$ which is defined as $R_{N}=\left(R-R_{0}\right) / R_{0}$, in which $R$ represents the electrical resistance obtained in the sensing measurement; $R_{0}$ is the initial value of the resistance. The sensitivity $(\% \Delta R)$ of the sensor is defined as the ratio between electrical resistance variation $\left(\Delta R=\left(R_{f}-R_{i}\right) / R_{i}\right)$ during gas exposure $\left(R_{f}\right)$ and the measured resistance before gas exposure $\left(R_{i}\right)$.

\section{Computational Details}

The electronic calculations are performed using density functional theory (DFT) $[38,39]$ in the framework of general gradient approximation (GGA) with Perdew-Burke-Ernzerhof as exchange-correlation functional $[40,41]$ as implemented in the SIESTA code [42]. We use a double- $\zeta$ basis set with additional polarization orbitals [43]. The real-space grid used for charge and potential integration is equivalent to a plane wave cutoff energy of $150 \mathrm{Ry}$ and $350 \mathrm{Ry}$ for $\mathrm{Ag}(111)$ systems. The pseudopotentials were constructed from $4,5,6,6,7$, and 11 valence electrons for the carbon, nitrogen, oxygen, sulfur, chloride, and silver atoms, respectively $\left(\mathrm{C}: 2 \mathrm{~s}^{2} 2 \mathrm{p}^{2}, \mathrm{~N}\right.$ : $2 s^{2} 2 p^{3}$, O: $2 s^{2} 2 p^{4}, S: 3 s^{2} 3 p^{4}$, Cl: $3 s^{2} 3 p^{5}$, and Ag: $5 s^{1} 4 d^{10}$ ). The nitrogen-doped $(5,5)$ single walled carbon nanotubes are constructed by using a supercell of 100 atoms ( 5 unit cells) and 3 nitrogen atoms with a pyridine-like doping configuration. Periodic boundary conditions are used and the intertube distance is kept to a minimum of $30 \AA$ to avoid lateral interactions. For the case of $\mathrm{Ag}(111)$ surface, the systems are represented by $(4 \times 4) \mathrm{Ag}(111)$ slab consisting of 4 layers, where the top two layers are freely relaxed. An $8 \times 8 \times 1$ Monkhorst-Pack grid is used to sample the Brillouin zone. A Methfessel-Paxton smearing of $0.1 \mathrm{eV}$ and a Pulay mixing are employed to aid convergence on the selfconsistent electron density. All the structures are relaxed by the conjugated gradient minimization until the maximum force is less than $0.04 \mathrm{eV} / \AA$. The adsorption energy $\left(\Delta E_{\mathrm{ads}}\right)$ is defined as $\Delta E_{\text {ads }}=E_{\text {total }}-E_{\text {surf }}-E_{\text {mol }}$, where $E_{\text {total }}$ is the energy of the total system (adsorbent + adsorbate). $E_{\text {surf }}$ is the energy of the adsorbent (i.e., a nanotube or $\mathrm{Ag}(111)$ surface) and $E_{\mathrm{mol}}$ is the energy of the adsorbate. Finally, the thermal stability of the adsorption process is verified by molecular dynamics (MD) using a time step of $1 \mathrm{fs}$ for the integration of the equations of motion, for a minimum of 1000 steps. The temperature of 200 and $350 \mathrm{~K}$ is controlled by the Nose thermostat, using a Nose mass of $10.0 \mathrm{Ry} \cdot \mathrm{fs}^{2}$ [44].

\section{Results and Discussion}

Figure 1(a) depicts scanning electron microscopy (SEM) image of $\mathrm{CN}_{X}$-MWNTs-Ag. Note that the sample exhibits a good distribution of Ag-NPs along the nanotube surface. The monocrystalline structure of the Ag-NPs can be clearly observed by transmission electron microscopy (TEM) images as it is depicted in Figures 1(b) and 1(c), with an average diameter of $14 \mathrm{~nm}$. High resolution TEM analysis (see Figure 1(c) and Figure S2) shows that Ag-NPs exhibit a well atomic arrangement indicating the formation of a single crystal with a thin amorphous layer on its surface (probably formed of carbonaceous material derived from the decoration process). X-ray diffraction analysis (Figure 1(d)) also confirms the crystallinity of the Ag-NPs and indicates that the nanoparticles exhibit a face centered cubic structure (fcc). After the decoration process, we fabricated diverse sensors, and Figure 1(e) depicts a SEM image of the nanotube foil used as the active sensor material; here, it can be appreciated that the foil is composed by well-dispersed CNTs. Figure 1(f) depicts a photograph of the fabricated sensor device showing the millimetric nanotube foils collocated between the copper electrodes.

The change in electrical resistance of the nanotube foils is monitored continuously during the entire sensing test in the presence of $\mathrm{CS}_{2}$, acetone $\left(\left(\mathrm{CH}_{3}\right)_{2} \mathrm{CO}\right)$, ethanol $\left(\mathrm{C}_{2} \mathrm{H}_{5} \mathrm{OH}\right)$, and chloroform $\left(\mathrm{CHCl}_{3}\right)$. The sensor sensitivity is obtained by analyzing the change in electrical resistance $(\% \Delta R)$ before and after vapor exposure. We have also estimated the response and recovery time of the sensing devices, where the response time is defined as the necessary time to reach the maximum electrical resistance after the vapor exposure. On the other hand, the recovery time is defined as the time needed to recover approximately $95 \%$ of its initial electrical resistance. In order to easily compare our results, we fabricated two different sensing devices: one is based on pure $\mathrm{CN}_{X}$-MWNTs, while the second one is fabricated using Ag-decorated $\mathrm{CN}_{X}$-MWNTs ( $\mathrm{CN}_{X}$-MWNTs-Ag). Both nanotube sensors are exposed to $\mathrm{CS}_{2}$ vapor, and the results are reported in Figure 2. The sensing experiments are carried out at three different temperatures $\left(25,40\right.$, and $\left.80^{\circ} \mathrm{C}\right)$. First, at room temperature $\left(25^{\circ} \mathrm{C}\right)$ when the sensors are in contact with $\mathrm{CS}_{2}$ vapor, their electrical resistance increases rapidly until saturation and it remains almost constant until the next purging cycle is applied. These results are depicted in Figure 2(a), where the shadow areas indicate the vapor exposure cycles. During the purging time, the electrical resistance decreases and returns nearly to the original value before vapor exposure. This behavior suggests that most of the adsorbed molecules on the nanotubes surface are removed during the contact with the purge gas. We also noted that the baseline is continuously decreasing after each purging cycle; this fact is related to the long-time molecule desorption. Pure and Ag-decorated $\mathrm{CN}_{X}$-MWNTs based sensors exhibit similar behavior with small response and recovery times $(\sim 10 \mathrm{~s})$, which are better than previously published reports [32-34]; see Table S1 in Supplementary Information. However, the increment in electrical resistance $(\% \Delta R)$ generated by the exposure to the organic vapor is larger for $\mathrm{CN}_{X}$-MWNTs$\operatorname{Ag}(\Delta R=36 \%)$ compared to pure $\mathrm{CN}_{X}$-MWNTs $(\Delta R=$ $22 \%$ ); these results indicate better sensitivity for $\mathrm{CS}_{2}$ vapor in the case of the Ag-NPs-nanotube system. This increment may be related to the presence of Ag-NPs on the $\mathrm{CN}_{X^{-}}$ MWNTs, thus having more sites to attach foreign molecules, which could increase the electrical resistance. Our results are in good agreement with the previous reported data, where metal decorated nanotube systems exhibit an improvement in sensor sensitivity $[7,8,13-16]$.

The fast decrease in resistivity shown in Figure 2(a) suggests a weak interaction between the $\mathrm{CS}_{2}$ molecules 

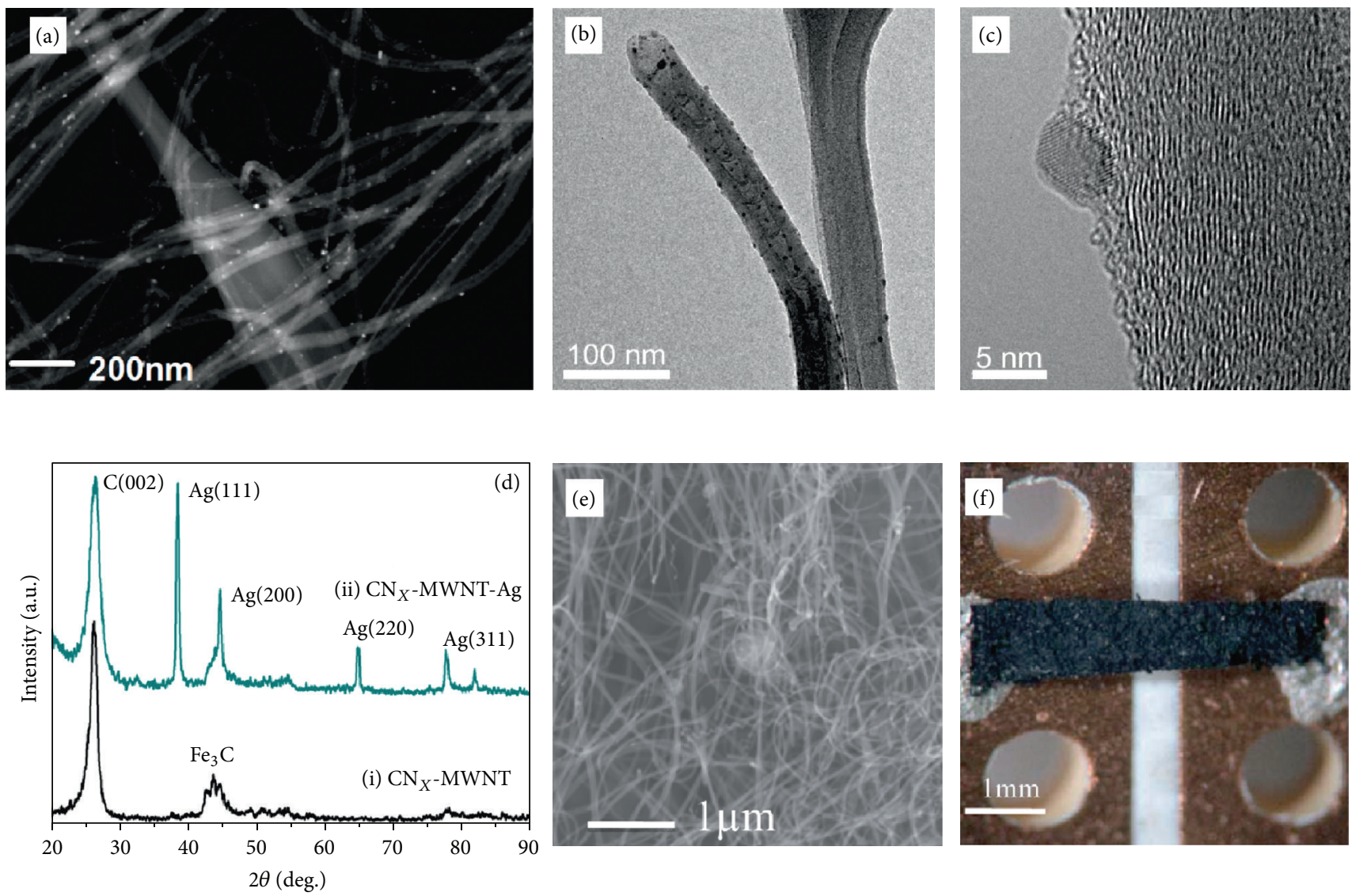

Figure 1: Ag-NPs anchored on the surface of $\mathrm{CN}_{X}$-MWNTs-Ag. (a) Scanning electron microscopy (SEM) image. ((b) and (c)) Transmission electron microscopy (TEM) images. (d) X-ray diffraction pattern of decorated and nondecorated $\mathrm{CN}_{X}-\mathrm{MWNTs}$. The $\mathrm{C}(002)$ peak is characteristic of MWCNTs; peaks at $\sim 43$ degrees correspond to encapsulated $\mathrm{FeC}_{3}$, normally observed in $\mathrm{MWCNTs}$. (e) Scanning electron microscopy (SEM) image of the sensor device which consists of a foil formed by $\mathrm{CN}_{X}$-MWNTs-Ag. (f) Sensor device photograph showing the nanotube foil over the copper electrodes.

and the sensors at room temperature. This relative weak interaction could be understood for foils made only of $\mathrm{CN}_{X^{-}}$ MWNTs due to the typical low reactivity. However, for $\mathrm{CN}_{X^{-}}$ MWNTs-Ag sensor device, the change in electrical resistance $(\% \Delta R)$ is expected to be larger after each exposure cycle (i.e., the baseline should increase) since it is anticipated that sulfur atoms (from $\mathrm{CS}_{2}$ vapor) interact in a stronger way with the Ag-NPs than with the carbon nanotube surface [7]. Our observations could be explained by suggesting that Ag-NPs do not interact directly with the $\mathrm{CS}_{2}$ molecules. The nondirect interaction could be demonstrated by TEM characterization (see Figure 1(c) and Figure S2), where AgNPs exhibit small amorphous layer on their surface. At $40^{\circ} \mathrm{C}$ (Figure 2(b)), the baseline (in both sensor devices) remains practically constant after each exposure cycle, suggesting that chemisorption may become relevant as adsorption process. At this temperature, also the $\mathrm{CN}_{X}$-MWNTs-Ag composite displays the best performance and sensitivity; it exhibits a larger change in electrical resistance during vapor exposure compared to pure $\mathrm{CN}_{X}$-MWNTs device. At higher temperature $\left(80^{\circ} \mathrm{C}\right.$, Figure $3(\mathrm{c})$ ), both baselines (pure and Agdecorated $\mathrm{CN}_{X}-\mathrm{MWNTs}$ ) increase slightly after each $\mathrm{CS}_{2}$ exposure cycle, suggesting that chemisorption of $\mathrm{CS}_{2}$ vapor is the main adsorption process. This event may also be related with the amorphous layer surrounding the Ag-NPs, which could be removed by thermal effects, and temporally allows that $\mathrm{CS}_{2}$ molecules could be covalently attached to Ag-NPs.

In Figure 3, the sensor devices are also tested at room temperature $\left(25^{\circ} \mathrm{C}\right)$ using acetone, ethanol, and chloroform vapors. Similar to the $\mathrm{CS}_{2}$ case, these results indicate that, at room temperature, the adsorption process is dominated by physisorption. The sensors based on $\mathrm{CN}_{X}-\mathrm{MWNTs}$ $\mathrm{Ag}$ exhibit larger signal than sensors made of only $\mathrm{CN}_{X^{-}}$ MWNTs. We also tested the sensors at higher temperatures $\left(70^{\circ} \mathrm{C}\right.$ or more); the results (not shown) demonstrate that sensors present chemisorption effects; that is, the baseline of electrical resistance increased monotonously with the number of cycles of exposure; in this case the purge gas does not remove completely previously attached molecules in the nanotube surfaces. The response time for both nanostructured sensors, with and without Ag-NPs, is in the range of $10-20 \mathrm{~s}$ and the recovery time around $10-15 \mathrm{~s}$.

The sensitivity $(\% \Delta R)$ of the sensor based on $\mathrm{CN}_{X^{-}}$ MWNTs-Ag for four different organic vapors is summarized in Figure 4; here the sensitivity $(\% \Delta R)$ is plotted versus operation temperature. Typically, for all gases and vapors, 


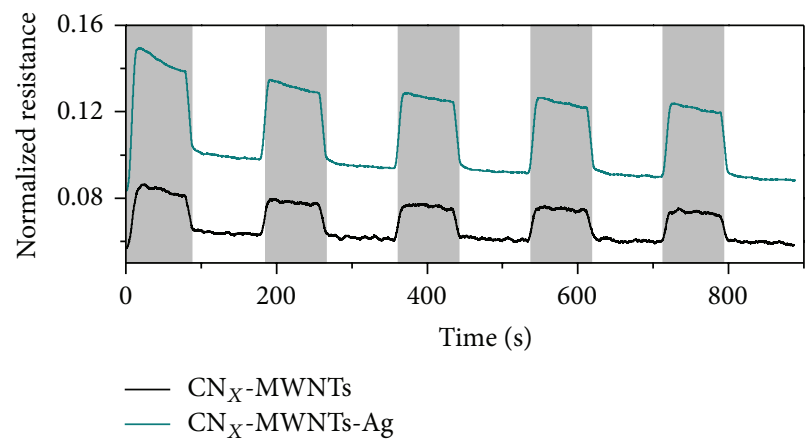

(a) $25^{\circ} \mathrm{C}$

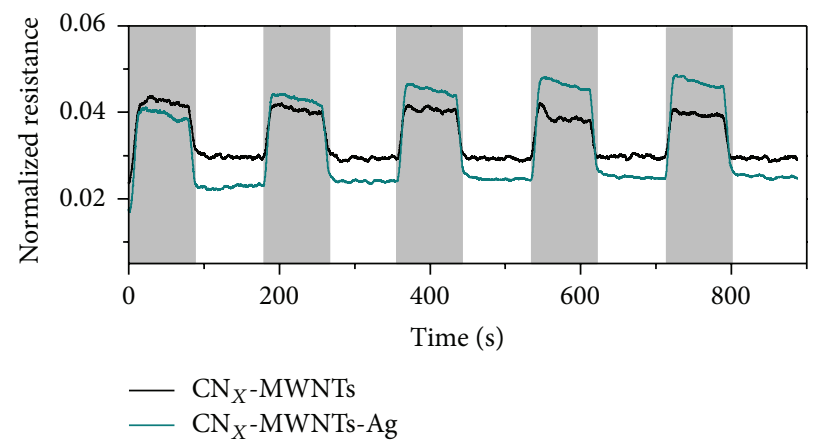

(b) $40^{\circ} \mathrm{C}$

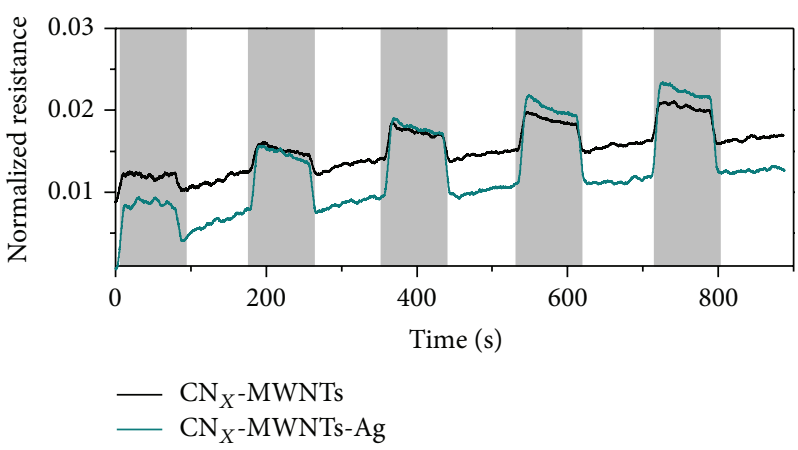

(c) $80^{\circ} \mathrm{C}$

FIGURE 2: Normalized electrical resistance of nanotube foils exposed to $\mathrm{CS}_{2}$ vapors at three different operation temperatures for $\mathrm{CN}_{X}-\mathrm{MWNTs}$ (black line) and $\mathrm{CN}_{X}$-MWNTs-Ag (cyan thin line). (a) At $25^{\circ} \mathrm{C}$ a good performance in both sensor devices is observed; notice that after each purge cycle, the baseline remains constant, suggesting a weak interaction between vapor and sensor material (physisorption). (b) At $40^{\circ} \mathrm{C}$, chemisorption and physisorption are both important; both devices still exhibit a good performance. (c) At $80^{\circ} \mathrm{C}$ the $\mathrm{CN}_{X}-\mathrm{MWNTs}-\mathrm{Ag}$ still shows better performance than the pristine $\mathrm{CN}_{X}-\mathrm{MWNT}$ device, but now the chemisorption process is the main detection mechanism. Notice that, in all operating temperatures, the $\mathrm{CN}_{X}-\mathrm{MWNTs}-\mathrm{Ag}$ exhibits larger change in electrical resistance when it is exposed to the $\mathrm{CS}_{2}$ vapor. The shadow areas indicate the exposure cycles to the $\mathrm{CS}_{2}$ vapor, equivalent to $80 \mathrm{~s}$.

the sensor shows an enhanced sensitivity at higher operation temperature. However, at a certain temperature the sensor sensitivity decreases. These critical temperatures depend on the targeted analyte, being the lowest for ethanol, followed by chloroform, acetone, and finally $\mathrm{CS}_{2}$ vapors. This critical temperature is also an indication in how strong is the interaction between the analyte and the nanocomposite, suggesting weaker interaction energies for ethanol and chloroform and larger for acetone and $\mathrm{CS}_{2}$. For ethanol, after $40^{\circ} \mathrm{C}$ the sensitivity decreases substantially; then after $50^{\circ} \mathrm{C}$ there is no clear response, which also indicates that the interaction energy with the nanosensors is easily overcome by the thermal energy. On the other hand, at $50^{\circ} \mathrm{C}$ the sensor sensitivity is the highest for chloroform vapor, but if the operation temperature reaches $80^{\circ} \mathrm{C}$, the electrical change generated by introduction of chloroform is negligible. In the case of acetone or $\mathrm{CS}_{2}$, the $\mathrm{CN}_{X}-\mathrm{MWNTs}-\mathrm{Ag}$ sensor at $80^{\circ} \mathrm{C}$ still exhibits a clear response and good sensitivity, and only after $130^{\circ} \mathrm{C}$ the response for acetone and $\mathrm{CS}_{2}$ decreases considerably (not showed). These results suggest that, by varying the operating temperature, it is possible to control the detection of the desired vapor and improve the selectivity of the sensor device.
4.1. Theoretical Description of $C N_{X}-M W N T s-A g$ Gas Sensors. Additionally, we performed density functional theory (DFT) calculations in order to understand the interaction between nitrogen-doped nanotubes and $\mathrm{CS}_{2}$, ethanol, acetone, and chloroform molecules. For the calculations a pyridine-like nitrogen-doped $(5,5)$ single-walled carbon nanotube $\left(\mathrm{CN}_{X^{-}}\right.$ SWNT) is considered. The pyridine-like doping consists in creating a vacancy and then substituting the carbon atoms surrounding the vacancy by three nitrogen ones; this site is one of the most common doping configurations [21,35]. The organic molecules are set around the doping site and relaxed using the conjugated gradient method. After geometrical relaxation, in all cases, any covalent bond is observed between the $\mathrm{CN}_{X}$-SWNT and the analytes (see Figure S3 in the Supplementary Information), indicating a weak interaction in agreement with the experimental observations. In order to analyze the adsorption energies on Ag-NPs, we used an fcc Ag surface where the (111) crystal plane is used as adsorption site. This approach has been widely used to accurately determine adsorption energies for nanoparticle systems [45]. Figure 5 summarizes the adsorption energy $\left(E_{\text {ads }}\right)$ for all systems; here a negative energy is associated with stable configurations. Figure 5(a) shows results for the $\mathrm{CN}_{X}$-SWNT revealing 


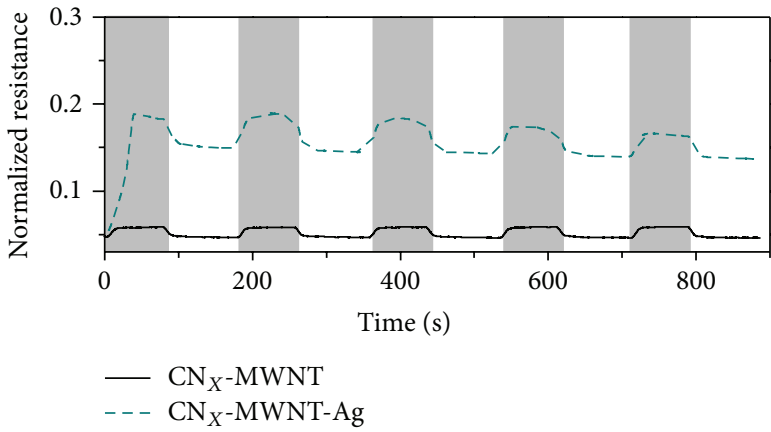

(a) Ethanol

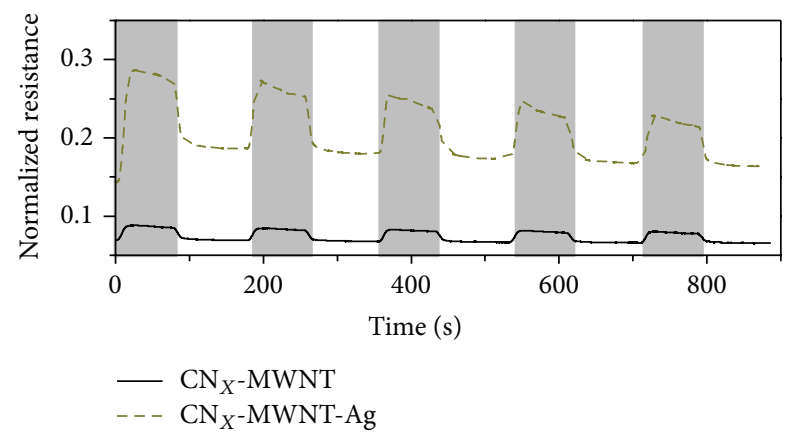

(b) Acetone

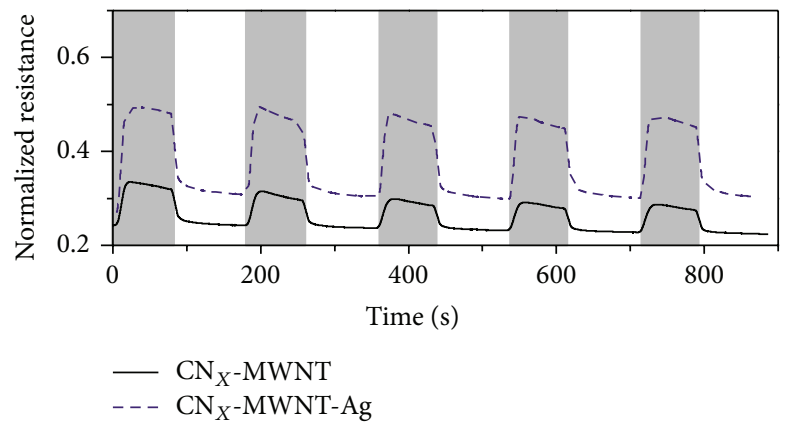

(c) Chloroform

FIGURE 3: Normalized electrical resistance of both $\mathrm{CN}_{X}-\mathrm{MWNT}$ and $\mathrm{CN}_{X}-\mathrm{MWNT}$-Ag sensor devices exposed to (a) ethanol, (b) acetone, and (c) chloroform at room temperature $\left(25^{\circ} \mathrm{C}\right)$. The shadow areas are exposure cycles of the different gases, equivalent to $80 \mathrm{~s}$. The dashed (solid) line corresponds to sensors based on $\mathrm{CN}_{X}$-MWNTs decorated with Ag nanoparticles (pure $\mathrm{CN}_{X}-\mathrm{MWCNTs}$ ).

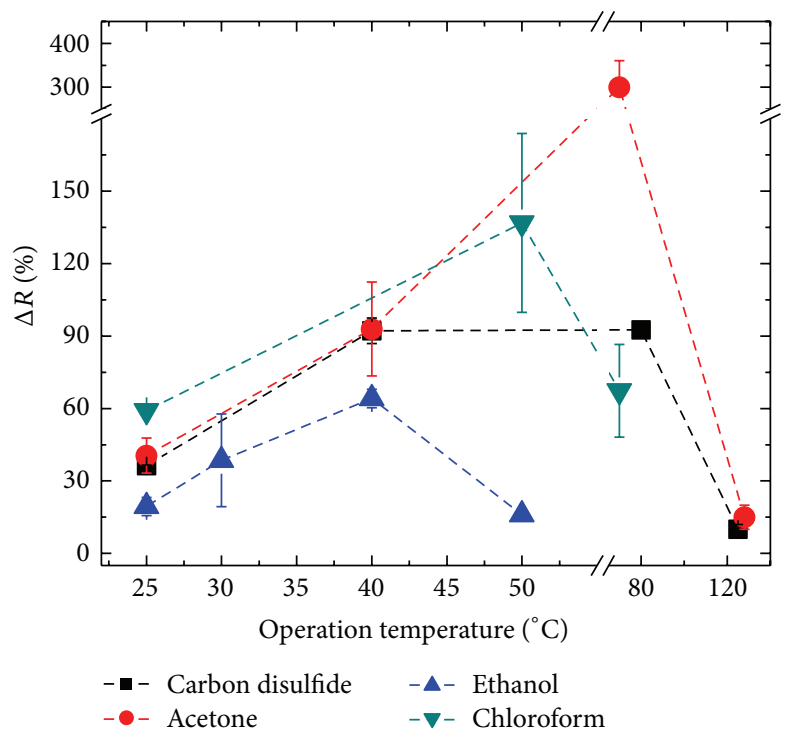

FIGURE 4: Sensitivity $(\% \Delta R)$ of the sensors after exposure to different vapors as function of the temperature. Notice that $\% \Delta R$ increases with the operating temperature; however, in all systems, there exists a critical temperature where $\% \Delta R$ starts to decrease. This behavior suggests that controlling the working temperature, it is possible to discriminate the gas vapor to be detected, improving the selectivity of the sensor material. 


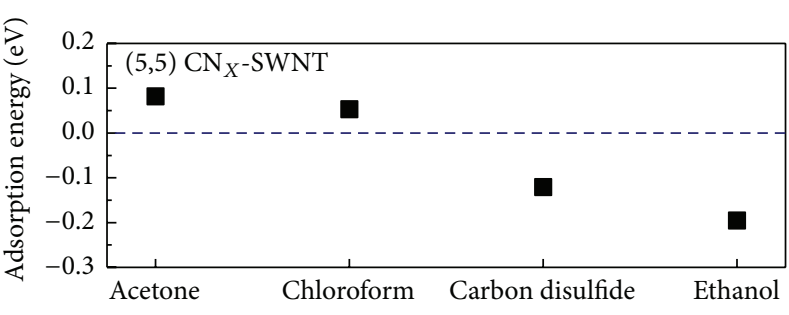

(a)

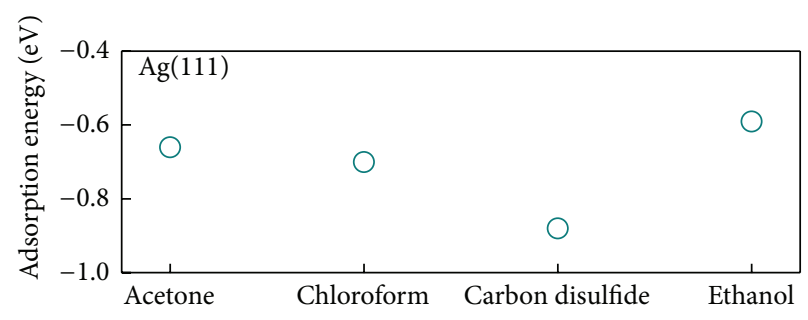

(b)

Figure 5: Adsorption energy $\left(E_{\text {ads }}\right)$ of different molecules interacting with (a) $(5,5)$-single walled carbon nanotubes doped with nitrogen (note that all molecules exhibit a poor interaction with the nanotube surface, thus suggesting a physisorption), (b) Ag(111) surface, showing large values of $E_{\mathrm{ads}}$; these results suggest that, in this case, chemisorption may be the main adsorption mechanism. Note that negative values of $E_{\text {ads }}$ are associated with stable configurations.

that the involved organic molecules are weakly attached to the nanotube surface. The calculated $E_{\text {ads }}$ for acetone and chloroform are 0.08 and $0.05 \mathrm{eV}$, respectively, indicating a low interaction. In the case of $\mathrm{CS}_{2}$ and ethanol the resulting $E_{\text {ads }}$ are -0.12 and $-0.20 \mathrm{eV}$, respectively. When the bare $\mathrm{Ag}(111)$ surface is set in contact with the molecules (see Figure 5(b) and Figure S4 in the Supplementary Information), all values of $E_{\mathrm{ads}}$ are negative and larger than those obtained from the nanotube system. Here, the oxygenated species such as acetone and ethanol exhibit the lowest values of $E_{\text {ads }},-0.66$ and $-0.59 \mathrm{eV}$, respectively, whereas chloroform and $\mathrm{CS}_{2}$ exhibit larger $E_{\text {ads }}$ equal to -0.70 and $-0.88 \mathrm{eV}$, respectively. These $E_{\text {ads }}$ values can be classified as chemisorption, since typically a physisorption event exhibits energies $>-0.5 \mathrm{eV}$. Our results are in good agreement with previous publications, where a low interaction with oxygenated species on $\mathrm{Ag}$ surfaces is observed [45].

Now considering the results for $\mathrm{CS}_{2}$, we observe that $\mathrm{CS}_{2}$ exhibit a weak interaction with pure carbon nanotubes, inferring that the molecules are joined via a physisorption mechanism, which is in qualitative agreement with the experimental sensing capacity at room temperature of foils made of pristine $\mathrm{CN}_{X}$-MWNTs. However, when the adsorption process is performed on the $\mathrm{Ag}(111)$ surface, the $\mathrm{CS}_{2}$ molecule exhibits multiple covalent bonds with the substrate. These results imply a strong interaction when Ag-NPs are used as substrates, thus suggesting chemisorption mechanism as a main adsorption process in the sensor activity. In order to complement the results, we also performed DFT calculations on using an icosahedral $\mathrm{Ag}_{13}$ cluster attached to a $(5,5)$ $\mathrm{CN}_{X}$-SWCNT and similar trends are found when compared with the $\mathrm{Ag}(111)$ surface, indicating that the nanotubes have a negligible effect on the adsorption properties of the composite. Similar results are obtained when acetone, ethanol, or chloroform is used on all systems.

Keeping our attention on the $\mathrm{CS}_{2}$ case, the experimental evidence on the sensor response at room temperature suggests that the $\mathrm{CS}_{2}$ vapor weakly interacts with $\mathrm{CN}_{X}$-MWNTsAg based foils (physisorption). Once the foil detects the gas vapor, this is easily removed by the purging gas. However, one would expect that the $S$ atoms could be easily linked to $\mathrm{Ag}$ atoms due to the chemical affinity between these two elements, as indicated by our DFT data. Then, why $\mathrm{CS}_{2}$ molecules exhibit a weak interaction with the foils avoiding chemisorption? In order to answer this question, we performed molecular dynamics simulations of the interaction between $\mathrm{Ag}$ clusters and $\mathrm{CS}_{2}$ molecules. Firstly, it is noticed that, from the TEM images (see Figure $1(\mathrm{~d})$ ), the $\mathrm{CN}_{X^{-}}$ MWNTs decorated with Ag nanoparticles exhibit a covering layer composed of amorphous carbon. In order to understand the role of this amorphous layer on Ag-NPs in the sensing capacity, we constructed an $\mathrm{Ag}_{55}$ icosahedral nanoparticle surrounded by a carbon layer $\left(\mathrm{C}_{80}\right)$. Each carbon atom was three-coordinated with $\mathrm{Ag}$ atoms; the initial structure and the relaxed geometry can be seen in Figures 6(a) and 6(b). Subsequently, we placed seven $\mathrm{CS}_{2}$ molecules near the surface of the $\mathrm{Ag}_{55} \mathrm{C}_{80}$ nanoparticle, the entire system was relaxed by conjugate gradient, and the resulting geometry is depicted in Figure 6(c). Then, using the latest geometry of the $7 \mathrm{CS}_{2}-\mathrm{Ag}_{55} \mathrm{C}_{80}$ system, a molecular dynamics simulation was performed at $200 \mathrm{~K}$ during $1 \mathrm{ps}$ with 1 -femtosecond steps (Figure 6(d)), and it is observed that two $\mathrm{CS}_{2}$ molecules are covalently attached to the $\mathrm{Ag}_{55} \mathrm{C}_{80}$. The relaxed structure at $350 \mathrm{~K}$ is shown in Figure 6(e); here the $7 \mathrm{CS}_{2}-\mathrm{Ag}_{55} \mathrm{C}_{80}$ system exhibits five $\mathrm{CS}_{2}$ molecules covalently attached to the $\mathrm{Ag}_{55} \mathrm{C}_{80}$ cluster, suggesting that an increment of the temperature promotes the bond formation between the $\mathrm{CS}_{2}$ molecules and the silver cluster decorated by carbon atoms; thus a chemisorption mechanism becomes relevant which are in accordance with the experimental evidence.

\section{Conclusions}

Vapor sensor devices based on Ag-NPs anchored on the surface of $\mathrm{CN}_{X}$-MWCNTs were fabricated and tested with different chemical substances: $\mathrm{CS}_{2}$, acetone, chloroform, and ethanol. Our results are compared to sensors made of pure nitrogen-doped multiwalled carbon nanotubes. The temperature dependence of the sensor performances was monitored; the results revealed that the sensor response and selectivity depend strongly on the temperature, promoting in some cases that vapor molecules are attached to the nanotubes surface via a covalent bond. We showed using density functional calculations that $\mathrm{CS}_{2}$, ethanol, acetone, and chloroform are weakly linked to the nitrogen-doped carbon nanotubes. However, when these molecules are set in 


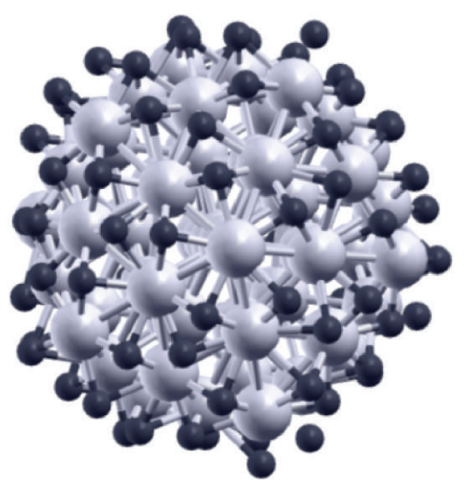

(a) Initial geometry $\mathrm{Ag}_{55} \mathrm{C}_{80}$

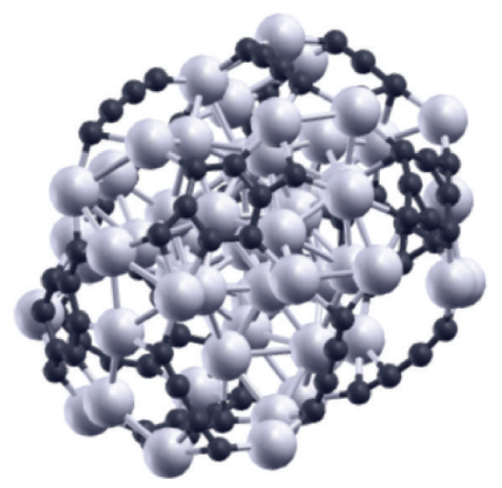

(b) Relaxed structure $\mathrm{Ag}_{55} \mathrm{C}_{80}$

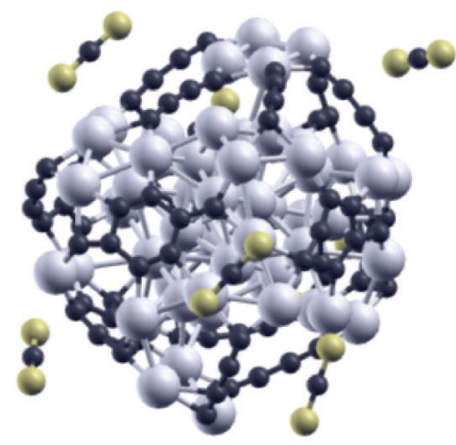

Silver Sulfur

(c) $7 \mathrm{CS}_{2}-\mathrm{Ag}_{55} \mathrm{C}_{80}$ $T=0 \mathrm{~K}$

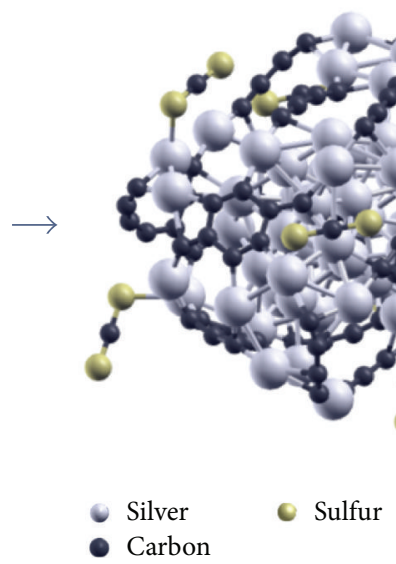

(d) $7 \mathrm{CS}_{2}-\mathrm{Ag}_{55} \mathrm{C}_{80}$

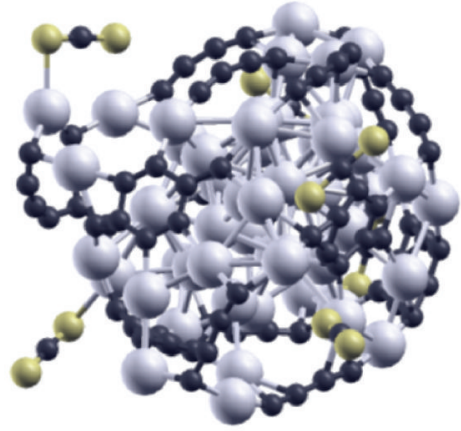

- Sulfur

- Silver

- Carbon (e) $7 \mathrm{CS}_{2}-\mathrm{Ag}_{55} \mathrm{C}_{80}$ $T=350 \mathrm{~K}$

Figure 6: Adsorption of $\mathrm{CS}_{2}$ on $\mathrm{Ag}_{55} \mathrm{C}_{80}$ cluster. (a) Initial geometry consisting in an icosahedral $\mathrm{Ag}_{55}$ cluster surrounded by a carbon layer $\left(\mathrm{C}_{80}\right)$. (b) Relaxed structure of $\mathrm{Ag}_{55} \mathrm{C}_{80}$ cluster. (c) shows the relaxed structure after the exposure of seven $\mathrm{CS}_{2}$ molecules at $T=0 \mathrm{~K}$; in this case, only two $\mathrm{CS}_{2}$ molecules are covalently attached to the $\mathrm{Ag}_{55} \mathrm{C}_{80}$ cluster. (d) and (e) depict the final structures obtained by molecular dynamical simulations at $T=200$ and $350 \mathrm{~K}$, respectively, during 1 ps. In (a) only two $\mathrm{CS}_{2}$ molecules are covalently attached to the cluster, whereas in (e) five $\mathrm{CS}_{2}$ molecules are covalently attached to the $\mathrm{Ag}_{55} \mathrm{C}_{80}$ cluster, suggesting that it is possible to obtain a chemisorption state at higher temperatures. These results could explain the sensor behavior when the temperature is increased. Note that the $\mathrm{CS}_{2}$ molecules are bound to the cluster via the sulfur atoms and low-coordinated Ag atoms.

contact with the $\operatorname{Ag}(111)$ surface, the molecules are attached to the surface via a covalent bond. Finally, an interesting case is related to the $\mathrm{CS}_{2}$ gas, where at room temperature the sensor efficiency is excellent; one would expect that the sulfur atoms would stick to the Ag-NPs via covalent bonds due to the good affinity of silver and sulfur; however the results show otherwise. Based on the TEM characterization, we attributed this effect to an amorphous carbon layer surrounding the Ag-NPs; this layer could avoid a free interaction between the sulfur and silver atoms as it is confirmed by our DFT molecular dynamics calculations. We demonstrated that, at room temperature, $\mathrm{CS}_{2}$ molecule does not attach to the surface of an Ag-cluster covered by an amorphous carbon layer; however, a temperature increase promotes covalent bonds between the $\mathrm{CS}_{2}$ and the Ag-cluster.

\section{Conflict of Interests}

The authors declare that there is no conflict of interests regarding the publication of this paper.

\section{Authors' Contribution}

Eduardo Gracia-Espino and Bernabé Rebollo-Plata contributed equally to this work.

\section{Acknowledgments}

The authors are grateful to N. Perea-López, A. MorelosGómez, G. J. Labrada-Delgado, and B. A. Rivera-Escoto for technical assistance. This work was supported in part 
by CONACYT-México Grant 60218-F1 (FLU). Eduardo Gracia-Espino acknowledges support from the Artificial Leaf Project Umeå (Knut and Alice Wallenberg Foundation) and the AForsk Foundation (14-541). Mauricio Terrones thanks JST-Japan for funding the Research Center for Exotic NanoCarbons, under the Japanese regional Innovation Strategy Program by the Excellence. The theoretical simulations were partially performed on resources provided by the Swedish National Infrastructure for Computing (SNIC) at the High Performance Computing Center North (HPC2N).

\section{References}

[1] D. R. Kauffman and A. Star, "Carbon nanotube gas and vapor sensors," Angewandte Chemie-International Edition, vol. 47, no. 35, pp. 6550-6570, 2008.

[2] N. Sinha, J. Ma, and J. T. W. Yeow, "Carbon nanotube-based sensors," Journal of Nanoscience and Nanotechnology, vol. 6, no. 3, pp. 573-590, 2006.

[3] O. K. Varghese, P. D. Kichambre, D. Gong, K. G. Ong, E. C. Dickey, and C. A. Grimes, "Gas sensing characteristics of multiwall carbon nanotubes," Sensors and Actuators B: Chemical, vol. 81, no. 1, pp. 32-41, 2001.

[4] P. Bondavalli, P. Legagneux, and D. Pribat, "Carbon nanotubes based transistors as gas sensors: state of the art and critical review," Sensors and Actuators B: Chemical, vol. 140, no. 1, pp. 304-318, 2009.

[5] M. Penza, R. Rossi, M. Alvisi, G. Cassano, and E. Serra, "Functional characterization of carbon nanotube networked films functionalized with tuned loading of Au nanoclusters for gas sensing applications," Sensors and Actuators, B: Chemical, vol. 140, no. 1, pp. 176-184, 2009.

[6] B. Rebollo-Plata, E. Muñoz-Sandoval, F. López-Urías, E. L. Hernández-Cortina, H. Terrones, and M. Terrones, "Efficient vapor sensors using foils of dispersed nitrogen-doped and pure carbon multiwalled nanotubes," Journal of Nanoscience and Nanotechnology, vol. 10, no. 6, pp. 3965-3972, 2010.

[7] D. W. H. Fam, A. I. Y. Tok, A. Palaniappan, P. Nopphawan, A. Lohani, and S. G. Mhaisalkar, "Selective sensing of hydrogen sulphide using silver nanoparticle decorated carbon nanotubes," Sensors and Actuators B: Chemical, vol. 138, no. 1, pp. 189-192, 2009.

[8] M. Penza, R. Rossi, M. Alvisi et al., "Pt- and Pd-nanoclusters functionalized carbon nanotubes networked films for sub-ppm gas sensors," Sensors and Actuators, B: Chemical, vol. 135, no. 1, pp. 289-297, 2008.

[9] W.-D. Zhang and W.-H. Zhang, "Carbon nanotubes as active components for gas sensors," Journal of Sensors, vol. 2009, Article ID 160698, 16 pages, 2009.

[10] H.-L. Hsu, J.-M. Jehng, Y. Sung, L.-C. Wang, and S.-R. Yang, "The synthesis, characterization of oxidized multi-walled carbon nanotubes, and application to surface acoustic wave quartz crystal gas sensor," Materials Chemistry and Physics, vol. 109, no. 1, pp. 148-155, 2008.

[11] J. Mäklin, T. Mustonen, K. Kordás, S. Saukko, G. Tóth, and J. Vähäkangas, "Nitric oxide gas sensors with functionalized carbon nanotubes," Physica Status Solidi (B), vol. 244, no. 11, pp. 4298-4302, 2007.

[12] K. H. An, S. Y. Jeong, H. R. Hwang, and Y. H. Lee, "Enhanced sensitivity of a gas sensor incorporating single-walled carbon nanotube-polypyrrole nanocomposites," Advanced Materials, vol. 16, no. 12, pp. 1005-1009, 2004.

[13] A. Star, V. Joshi, S. Skarupo, D. Thomas, and J.-C. P. Gabriel, "Gas sensor array based on metal-decorated carbon nanotubes," Journal of Physical Chemistry B, vol. 110, no. 42, pp. 21014-21020, 2006.

[14] S. Mubeen, T. Zhang, N. Chartuprayoon et al., "Sensitive detection of $\mathrm{H}_{2} \mathrm{~S}$ using gold nanoparticle decorated singlewalled carbon nanotubes," Analytical Chemistry, vol. 82, no. 1, pp. 250-257, 2010.

[15] C. Bittencourt, A. Felten, E. H. Espinosa et al., " $\mathrm{WO}_{3}$ films modified with functionalised multi-wall carbon nanotubes: morphological, compositional and gas response studies," Sensors and Actuators B: Chemical, vol. 115, no. 1, pp. 33-41, 2006.

[16] D. R. Kauffman, D. C. Sorescu, D. P. Schofield, B. L. Allen, K. D. Jordan, and A. Star, "Understanding the sensor response of metal-decorated carbon nanotubes," Nano Letters, vol. 10, no. 3, pp. 958-963, 2010.

[17] C. S. Yeung, L. V. Liu, and Y. A. Wang, "Adsorption of small gas molecules onto Pt-doped single-walled carbon nanotubes," Journal of Physical Chemistry C, vol. 112, no. 19, pp. 7401-7411, 2008.

[18] F. Villalpando-Páez, A. H. Romero, E. Muñoz-Sandoval, L. M. Martínez, H. Terrones, and M. Terrones, "Fabrication of vapor and gas sensors using films of aligned $\mathrm{CN}_{x}$ nanotubes," Chemical Physics Letters, vol. 386, no. 1-3, pp. 137-143, 2004.

[19] S. Peng and K. Cho, "Ab initio study of doped carbon nanotube sensors," Nano Letters, vol. 3, no. 4, pp. 513-517, 2003.

[20] T. Sharifi, E. Gracia-Espino, H. Reza Barzegar et al., "Formation of nitrogen-doped graphene nanoscrolls by adsorption of magnetic $\gamma$ - $\mathrm{Fe}_{2} \mathrm{O}_{3}$ nanoparticles," Nature Communications, vol. 4 , article 2319, 2013.

[21] E. Gracia-Espino, F. López-Urías, H. Terrones, and M. Terrones, "Doping $(10,0)$-semiconductor nanotubes with nitrogen and vacancy defects," Materials Express, vol. 1, pp. 127-135, 2011.

[22] A. Zamudio, A. L. Elías, J. A. Rodríguez-Manzo et al., "Efficient anchoring of silver nanoparticles on n-doped carbon nanotubes," Small, vol. 2, no. 3, pp. 346-350, 2006.

[23] N. Tanaka, H. Nishikiori, S. Kubota, M. Endo, and T. Fujii, "Photochemical deposition of Ag nanoparticles on multiwalled carbon nanotubes," Carbon, vol. 47, no. 11, pp. 2752-2754, 2009.

[24] Y. Lin, K. A. Watson, S. Ghose et al., "Direct mechanochemical formation of metal nanoparticles on carbon nanotubes," Journal of Physical Chemistry C, vol. 113, no. 33, pp. 14858-14862, 2009.

[25] Y. Lin, K. A. Watson, M. J. Fallbach et al., "Rapid, solventless, bulk preparation of metal nanoparticle-decorated carbon nanotubes," ACS Nano, vol. 3, no. 4, pp. 871-884, 2009.

[26] A. B. Castle, E. Gracia-Espino, C. Nieto-Delgado, H. Terrones, M. Terrones, and S. Hussain, "Hydroxyl-functionalized and $\mathrm{N}$-doped multiwalled carbon nanotubes decorated with silver nanoparticles preserve cellular function," ACS Nano, vol. 5, no. 4, pp. 2458-2466, 2011.

[27] Y.-C. Tsai, P.-C. Hsu, Y.-W. Lin, and T.-M. Wu, "Silver nanoparticles in multiwalled carbon nanotube-nafion for surfaceenhanced Raman scattering chemical sensor," Sensors and Actuators B: Chemical, vol. 138, no. 1, pp. 5-8, 2009.

[28] M. Sanles-Sobrido, L. Rodríguez-Lorenzo, S. Lorenzo-Abalde et al., "Label-free SERS detection of relevant bioanalytes on silvercoated carbon nanotubes: the case of cocaine," Nanoscale, vol. 1, no. 1, pp. 153-158, 2009. 
[29] S. K. Pandey and K.-H. Kim, "A review of methods for the determination of reduced sulfur compounds (RSCS) in air," Environmental Science and Technology, vol. 43, no. 9, pp. 30203029, 2009.

[30] W. Wardencki, "Problems with the determination of environmental sulphur compounds by gas chromatography," Journal of Chromatography A, vol. 793, no. 1, pp. 1-19, 1998.

[31] H. Abadin and J. J. Liccione, Toxicological Profile for Carbon Disulfide, Agency for Toxic Substances and Disease Registry, Atlanta, Ga, USA, 1996.

[32] Y. Xuan, J. Hu, K. Xu, X. Hou, and Y. Lv, "Development of sensitive carbon disulfide sensor by using its cataluminescence on nanosized-CeO $\mathrm{C}_{2}$, Sensors and Actuators, B: Chemical, vol. 136, no. 1, pp. 218-223, 2009.

[33] E. Comini, V. Guidi, M. Ferroni, and G. Sberveglieri, “ $\mathrm{TiO}_{2}: \mathrm{Mo}$, $\mathrm{MoO}_{3}: \mathrm{Ti}, \mathrm{TiO}+\mathrm{WO}_{3}$ and $\mathrm{TiO}: \mathrm{W}$ layer for landfill produced gases sensing," Sensors and Actuators B: Chemical, vol. 100, no. 1-2, pp. 41-46, 2004.

[34] Y.-C. Chou and J.-S. Shih, "Bi-channel surface acoustic wave gas sensor for carbon disulfide and methanol vapors in polymer plants," Journal of the Chinese Chemical Society, vol. 61, no. 11, pp. 1237-1244, 2014.

[35] R. Czerw, M. Terrones, J.-C. Charlier et al., "Identification of electron donor States in N-doped carbon nanotubes," Nano Letters, vol. 1, no. 9, pp. 457-460, 2001.

[36] A. A. Koós, M. Dowling, K. Jurkschat, A. Crossley, and N. Grobert, "Effect of the experimental parameters on the structure of nitrogen-doped carbon nanotubes produced by aerosol chemical vapour deposition," Carbon, vol. 47, no. 1, pp. 30-37, 2009.

[37] M. L. García-Betancourt, N. Perea-López, S. M. Vega-Díaz et al., "Pine-tree-like morphologies of nitrogen-doped carbon nanotubes: electron field emission enhancement," Journal of Materials Research, vol. 29, no. 20, pp. 2441-2450, 2014.

[38] P. Hohenberg and W. Kohn, "Inhomogeneous electron gas," Physical Review, vol. 136, no. 3, pp. B864-B871, 1964.

[39] W. Kohn and L. J. Sham, "Self-consistent equations including exchange and correlation effects," Physical Review, vol. 140, no. 4, Article ID A1133, 1965.

[40] J. P. Perdew, K. Burke, and M. Ernzerhof, "Generalized gradient approximation made simple," Physical Review Letters, vol. 77, no. 18, abstract 3865, 1996.

[41] J. P. Perdew, K. Burke, and M. Ernzerhof, "Generalized gradient approximation made simple," Physical Review Letters, vol. 78, p. 1396, 1997.

[42] J. M. Soler, E. Artacho, J. D. Gale et al., "The SIESTA method for ab initio order-N materials simulation," Journal of Physics: Condensed Matter, vol. 14, no. 11, pp. 2745-2779, 2002.

[43] J. Junquera, Ó. Paz, D. Sánchez-Portal, and E. Artacho, "Numerical atomic orbitals for linear-scaling calculations," Physical Review B, vol. 64, no. 23, Article ID 235111, 2001.

[44] S. Nosé, "A unified formulation of the constant temperature molecular dynamics methods," Journal of Chemical Physics, vol. 81, no. 1, pp. 511-519, 1984.

[45] J. K. Nørskov, J. Rossmeisl, A. Logadottir et al., "Origin of the overpotential for oxygen reduction at a fuel-cell cathode," Journal of Physical Chemistry B, vol. 108, no. 46, pp. 1788617892, 2004. 


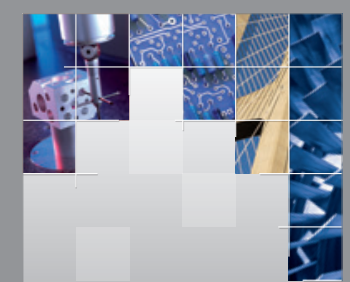

\section{Enfincering}
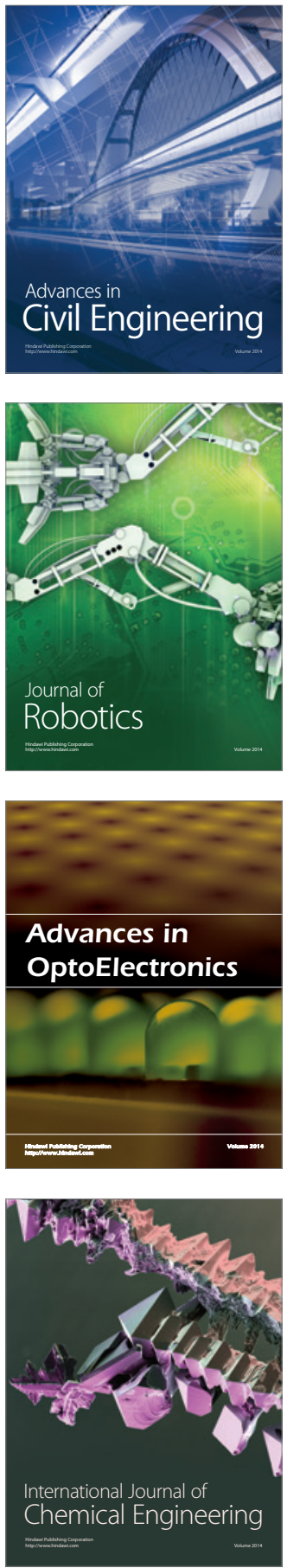

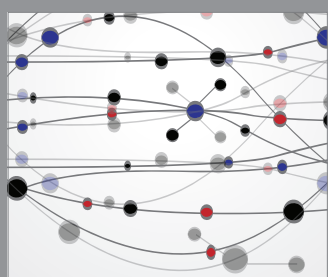

The Scientific World Journal

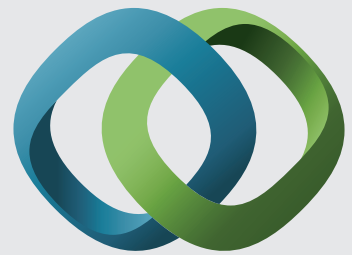

\section{Hindawi}

Submit your manuscripts at

http://www.hindawi.com
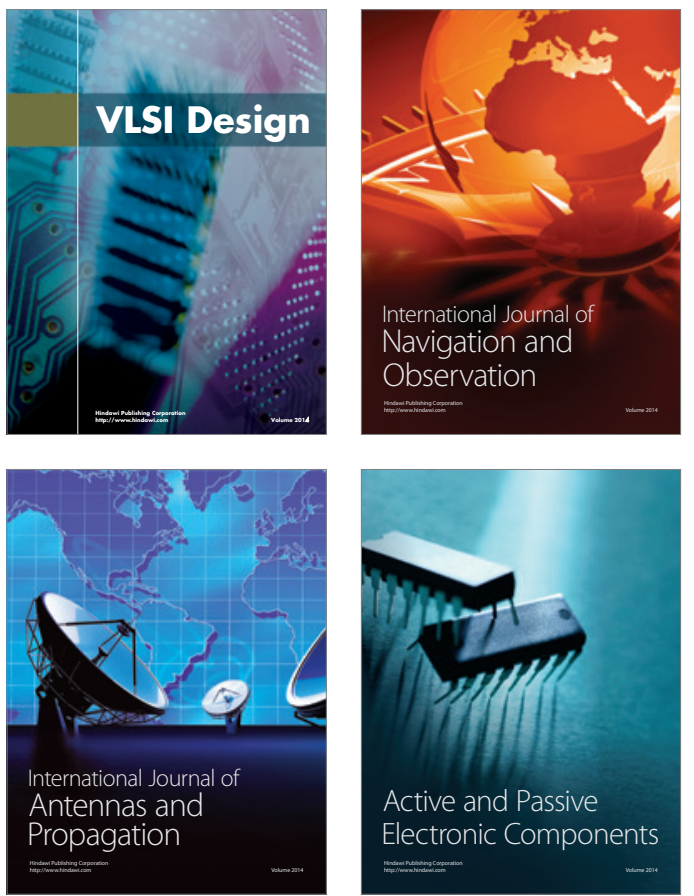
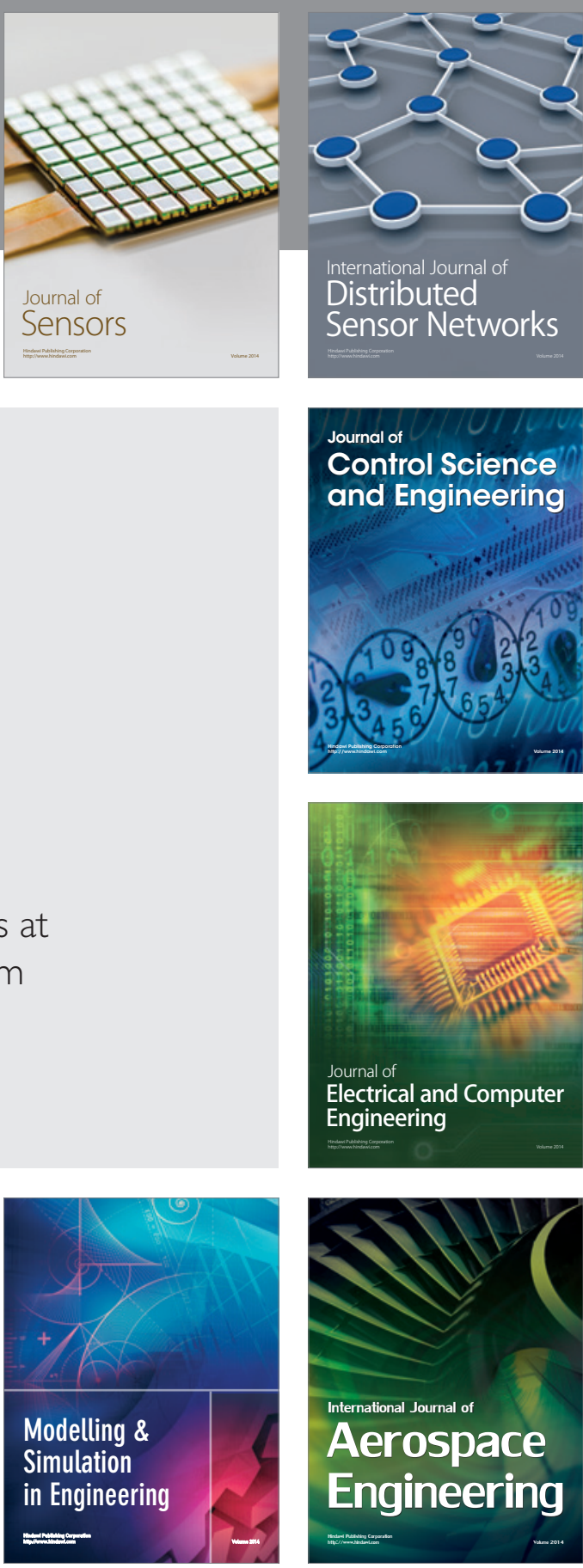

International Journal of

Distributed

Sensor Networks

Journal of

Control Science

and Engineering
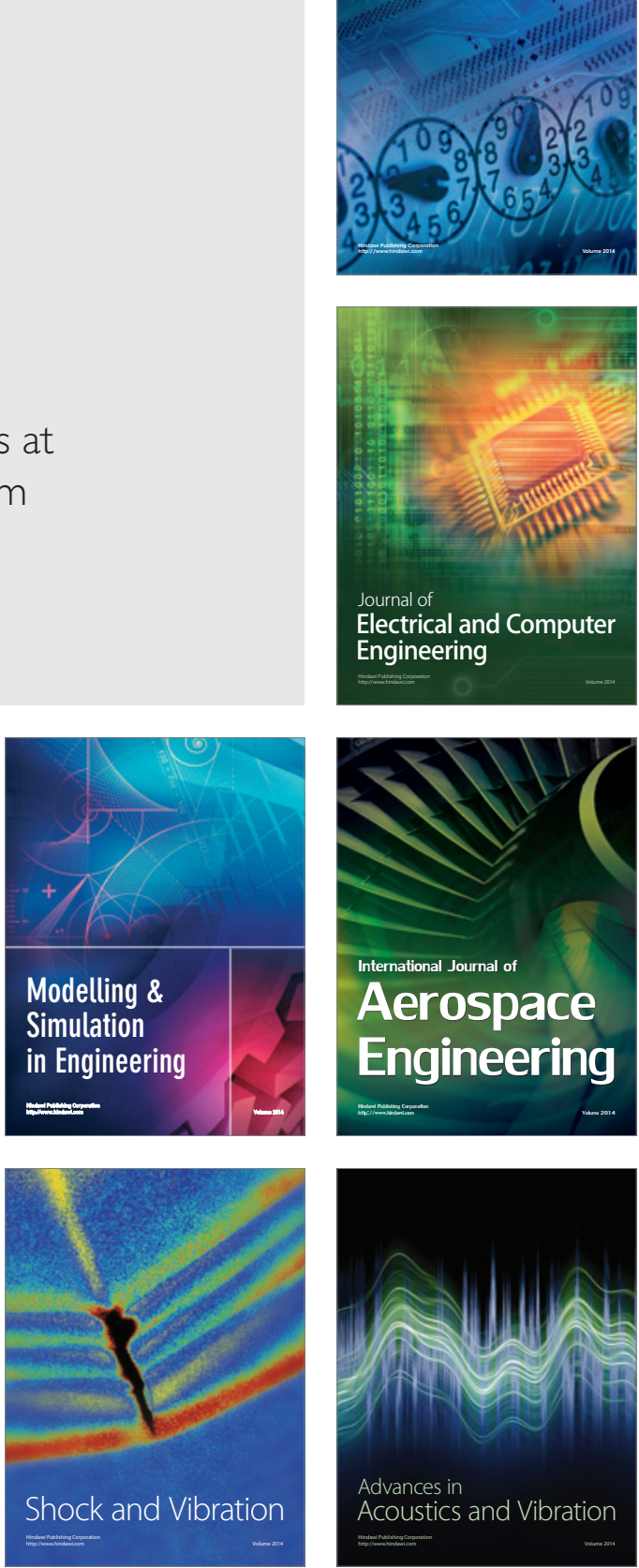